\title{
Control of phytoplankton growth in nutrient recycling ecosystems. Theory and terminology
}

\author{
T. Frede Thingstad ${ }^{1}$, Egil Sakshaug ${ }^{2}$
}

\begin{abstract}
${ }^{1}$ Department of Microbiology and Plant Physiology, University of Bergen, Jahnebk. 5, N-5007 Bergen, Norway
${ }^{2}$ Trondhjem Biological Station, The Museum, University of Trondheim, Bynesvn. 46, N-7018 Trondheim, Norway
\end{abstract}

\begin{abstract}
Some of the principles governing phytoplankton growth, biomass, and species composition in 2-layered pelagic ecosystems are explored using an idealized, steady-state, mathematical model, based on simple extensions of Lotka-Volterra type equations. In particular, the properties of a food web based on 'small' and 'large' phytoplankton are investigated. Features of the phytoplankton community that may be derived from this conceptually simple model include co-existence of more than one species on one limiting nutrient, a rapid growth rate for a large fraction of the phytoplankton community in oligotrophic waters, a long food chain starting from a population of small phytoplankton in waters with moderate mixing over the nutricline, and a transition to dominance of a food chain based on large phytoplankton when mixing is increased. As pointed out by other authors, careless use of the concept of one limiting factor may be potentially confusing in such systems. To avoid this, a distinction in terminology between 'controlling' and 'limiting' factors is suggested.
\end{abstract}

\section{INTRODUCTION}

Various aspects of nutrient cycling in pelagic ecosystems are of prime importance to our understanding of how productivity of the oceans is controlled, and to our ability to analyze present and future impacts of man's activity on oceanic, coastal, and freshwater ecosystems.

The coupling of primary production to mineral nutrient cycling is probably strict and important in the euphotic zone of waters subject to prolonged periods of stratification. In such environments, a large fraction of primary production may depend upon regeneration of nutrients originally sequestered in biomass during primary production, regeneration thus constituting feed-back loops in the system. The behavior of systems with loops is not always easy to understand without some kind of support from mathematical analysis, and the mechanisms underlying many apparently general aspects of phytoplankton communities are not intuitively obvious. Examples of this would be the co-existence of many species in an apparently homogenous environment, i.e. Hutchinson's paradox (Hutchinson 1961); the apparently rapid phytoplankton growth rates at undetectable nutrient concentrations in oligotrophic environments (Goldman et al. 1979, Goldman 1986, Laws et al. 1984, Sakshaug et al. 1983); and the dominance of short food chains in upwelling areas (Ryther 1969).

Many authors have addressed various aspects of the planktonic ecosystem using mathematical models which are idealized and conceptual. Many of these have been based on the steady-state solutions to extensions of classical Lotka-Volterra equations of predatorprey relationships. Riley (1963) analyzed general foodchain relationships in planktonic systems, and Smith (1969) addressed the question of effects of nutrient enrichment on food webs, pointing out the important differences between food chains with even and odd numbers of trophic steps. Using network analysis, Lane \& Levins (1977) reached many of the same conclusions. Concepts of this kind have inspired a large body of investigations in limnology, mainly aimed at minimizing the profuse growth of phytoplankton in eutrophied lakes by manipulation of the number of predator levels in the food chain (e.g. Carpenter et al. 1985 and references therein).

The concept of 'new' versus 'old' production (Dugdale \& Goering 1967, Eppley \& Peterson 1979) is essential to the understanding of how the closed loops of the recycling part of these systems interact with the imports and exports of mineral nutrients. A mathematical description demonstrating the importance of algal 
loss rates to the behavior of such systems was given by Dugdale (1967). Simple conceptual food web models in laboratory chemostat systems based on microorganisms have been analyzed by several authors (e.g. Jost et al. 1973b, Thingstad \& Pengerud 1985). Laws (1975) developed a model that allowed an analysis of how the cellular properties of phytoplankton species and the hydrographic properties of the water column could influence size distribution in the phytoplankton community. The effect of predation on phytoplankton size distribution has been modelled by Carpenter \& Kitchell (1984).

The work presented here attempts to explore the combined effects of recycling and sedimentation on steady-state properties of the phytoplankton community. Non-steady states are of obvious importance to the understanding of many aspects of planktonic ecosystems (see e.g. Harris 1983). The range of features that may be derived from extremely simple steady-state models such as those examined in this paper are, however, astonishingly large. A diverse suite of aspects of phytoplankton ecology proposed by many authors may be described within such a simple formalized framework.

Limitation of phytoplankton growth rate is usually assumed to play an extremely important part in the control of the phytoplankton community (e.g. Tilman et al. 1982 and references therein). Yet, as stressed by Lane \& Levins (1977), there is an apparent contradiction between the 'everything depends on everything' philosophy that emerges from holistic analyses of larger systems, and the concept of 'a single limiting factor'. Lane \& Levins conclude their paper with the statement: ' . . . we urge a whole system approach and believe that the limiting factor concept is an ecological myth, despite its simultaneous existence as a physiological truth'. We will argue that the limiting factor concept may still be valid and fruitful, provided care is taken to restrict its use to the factor(s) explicitly and directly limiting the growth rate of a population, as distinguished from a broader concept of controlling factors which may act indirectly through the links of the ecosystem.

\section{MATHEMATICAL MODELS}

\section{General description}

The analysis is developed using a description based on the mineral nutrient sequestered by each population in a food chain or food web. Mineral nutrient in the biomass of the populations, together with free mineral nutrient in the water $(N)$, sum up to the degree of nutrient enrichment (eutrophication) ( $N_{0}$ ) of the ecosys- tem. Through processes such as uptake, predation and regeneration, $N_{0}$ is shared among the free mineral nutrient $\mathrm{N}$ and the biological populations. In a closed system, $N_{0}$ is a constant; in an open system, mineral nutrients may be imported or exported by processes such as sedimentation or hydrodynamic transport through the nutricline. As a consequence, the degree of nutrient enrichment $N_{0}$ becomes a dynamic variable with a steady state value $\mathrm{N}_{\mathrm{g}}$. In reading the subsequent text, it is essential to keep in mind the difference between free mineral nutrient $N$ and nutrient enrichment $\mathrm{N}_{0}$.

The discussion is based on an analysis of the steady states of Lotka-Volterra type equations with population growth rates assumed either to be proportional to substrate (prey) concentrations, or, at high substrate (prey) levels, to be constant $\left(=\mu^{\mathrm{m}}\right)$. In a linear food chain (Frame 1), the steady state conditions lead to a recursive formula (Frame 2, Eq. 2.1) for the steady state values of the populations. For the simple food web with 2 size classes of phytoplankton shown in Fig. 2, the analytical equilibrium solutions for the closed system are shown in Frame 3. Using a standard microcomputer spreadsheet, Eq. 2.1 and Eqs. 3.1 to 3.6 have been solved numerically to give the steady state distribution of mineral nutrient between the biomass of the populations, and the free mineral nutrient N. Values used for the parameters are given in Table 1.

\section{Closed systems with linear food chains}

In an ecosystem with a linear food chain, the effect of a change in nutrient enrichment on a population at one trophic level is dependent upon the number of trophic levels in the chain (e.g. Lane \& Levins 1977). If there are $n$ levels in the chain, the effect of an increased nutrient enrichment $N_{0}$ will be a linear increase in biomass of populations at levels $n, n-2, n-4$ etc., while populations at levels $n-1, n-3, n-5$ etc will remain constant (Eq. 2.1). A new population $\left(X_{n+1}\right)$ can establish itself at level $n+1$ of the linear chain once its food supply, i.e. the population $\mathrm{X}_{\mathrm{n}}$ at level $\mathrm{n}$, becomes abundant enough for population $n+1$ to reach a growth rate that balances its loss rates. The population at level $n$ will no longer increase in biomass, but its growth rate will now increase with increasing nutrient enrichment. With the model described in Frame 1, the concentration of population or substrate $X_{n}$ that allows establishment of population $X_{n+1}$ is given by the combined parameter $\delta_{n+1} / \beta_{n+1} \alpha_{n+1}$.

For some value of $N_{0}$, one of the populations at levels $n-1, n-3$, etc., will reach its maximum growth rate $\mu^{\mathrm{m}}$. In this case both biomass and growth rate at this trophic level becomes constant, i.e. independent of any further 
Frame 1 Differential equations describing the transfer of mineral nutrient in a linear food chain with $\mathrm{n}$ trophic levels

The properties of a population are characterized by 4 parameters: $\beta, \alpha, \mu^{\mathrm{m}}$, and $\delta$ (Table 1). Growth rate of a population is assumed to be proportional to nutrient uptake (proportionality constant $=$ assimilation efficiency $\beta$ ). The specific uptake rate of a population is assumed either to be proportional to substrate (prey) concentration (proportionality factor = affinity constant $\alpha$ ), or, at saturating food levels, to be constant $\left\{=\mu^{\mathrm{m}}\right\}$. Specific death rate $\delta$ is assumed to be constant.

For a population at trophic level $\mathrm{i}$, with prey at level $\mathrm{i}-1$ and a predator at level $\mathrm{i}+1$, the changes in mineral nutrient content, $\mathrm{X}_{1}$ is then given by a Lotka-Volterra type differential equation of the form:

$$
\begin{aligned}
\mathrm{d} \mathrm{X}_{1} / d \mathrm{t}= & \beta_{1} \alpha_{\mathrm{i}} \mathrm{X}_{1-1} \mathrm{X}_{\mathrm{i}}-\delta_{1} \mathrm{X}_{\mathrm{i}}-\alpha_{1+1} \mathrm{X}_{1} \mathrm{X}_{1+1}, \mathrm{i}=1 \ldots \mathrm{n} \\
& \text { (growth) (death) (predation) }
\end{aligned}
$$

or, when growth rate is saturated:

$$
\mathrm{dX} \mathrm{X}_{\mathrm{i}} / \mathrm{dt}=\mu_{1}^{\mathrm{m}} \mathrm{X}_{\mathrm{i}}-\delta_{1} \mathrm{X}_{1}-\alpha_{\mathrm{i}+1} \mathrm{X}_{1} \mathrm{X}_{1+\mathrm{n}}, \mathrm{i}=1 \ldots \mathrm{n} \text {. }
$$

In a closed system with a total amount $N_{0}$ of mineral nutrient to be shared among the populations and the concentration of free mineral nutrient $\left(\mathrm{X}_{0}\right)$, the equations are subject to the constraint:

$$
\mathrm{N}_{\mathrm{o}}=\sum \mathrm{X}_{1}, \mathrm{i}=0,1 \ldots \mathrm{n} \text {. }
$$

In an open system, this constraint must be replaced by an equation describing the in-and outputs of mineral nutrient $\mathrm{N}_{0}$ :

$$
\mathrm{dN} N_{0} / \mathrm{dt}=\mathrm{D}\left(\mathrm{N}_{\mathrm{d}}-\mathrm{N}_{\mathrm{o}}\right)-\sum\left(1-\mathrm{f}_{1}\right) \delta_{1} \mathrm{X}_{1}-\sum\left(1-\mathrm{g}_{\mathrm{i}}\right)\left(1-\beta_{\mathrm{i}}\right) \alpha_{\mathrm{i}} \mathrm{X}_{1-1} \mathrm{X}_{\mathrm{i}}
$$

(Exchange over nutricline - sedimenting part of death - sedimenting part of excretion/egestion)

Implicit in the term for exchange is the assumption that all populations are transported passively by the mixing processes over the nutricline. Assuming population concentrations below the nutricline to be zero, this loss can be incorporated in Eqs. (1.1) and $(1.2)$ by replacing $\delta_{1}$, by $\delta_{\mathrm{i}}+\mathrm{D}$.

Frame 2. Equilibrium solution to the equations of Frame 1

As long as Eq. (1.1) is valid (no growth rates saturated), the equilibrium condition $\mathrm{dX} / \mathrm{d} t=0$ gives a recursive formula for the equilibrium concentration $\mathrm{X}_{\mathrm{i}}$ at trophic level $\mathrm{i}$

$$
X_{i}=\left(\beta_{i+1} \alpha_{i+1}\right)^{-1}\left(\delta_{1+1}+\alpha_{i+2} X_{i+2}\right), i=0,1 \ldots n-1
$$

Since $X_{n+1}=0$, Eq. (2.1) gives $X_{n-1}^{*}=\left(\beta_{n} \alpha_{n}\right)^{-1} \delta_{n}$. Inserting this back into Eq. (2.1), $X_{n-3}$ also becomes a function of the biological parameters only, i.e. the $\beta, \alpha$, and $\delta$ 's, and therefore independent of $N_{0}$. Repeating this process, one finds that the equilibrium values $X_{n-1}^{*}, X_{n-3}, X_{n-5}$ etc are independent of $N_{0}$.

Using Eq. (1.3), and a similar repeated insertion of Eq. (2.1) it may be shown that $X_{n}$ is a linearly increasing function of $N_{0}$. From Eq. (2.1) $X_{\dot{n}-2}$ is a linearly increasing function of $N_{0}$. Continued use of Eq. (2.1) gives that all the trophic levels $X_{n} \cdot X_{n}-2 \ldots$ etc, are linearly increasing functions of the nutrient enrichment $N_{0}$.

For computational purposes: choosing a value for $\mathrm{X}_{\mathrm{n}}$, all $\mathrm{X}_{\mathrm{i}}$ (and therefore also $\mathrm{N}_{\mathrm{o}}$ ), can be computed from Eq. (2.1). (If required, analytical solutions to all the Xi may be derived from Eqs. (2.1) and (1.3) through simple, but rather lengthy, algebraic manipulations.)

In the open system, the equilibrium condition $\mathrm{dN}_{\mathrm{o}} / \mathrm{dt}$ gives (from Eq. 1.4):

$$
D \cdot\left(N_{d}-N_{n}\right)=\sum\left(1-f_{i}\right) \delta_{i} X_{i}+\sum\left(1-g_{i}\right)\left(1-\beta_{1}\right) \alpha_{i} X_{i-1} X_{1}
$$

and $\delta_{1+1}$ in Eq. (2.1) replaced by $\delta_{i+1}+\mathrm{D}$.

increase in nutrient enrichment. Consequently, no further increase can take place in the transport of nutrient through this link, and populations above it in the chain then remain uninfluenced by further increases in nutrient enrichment.

Fig. 1 shows how the resulting pattern alternates between an increase in the equilibrium concentration of free mineral nutrient $\mathrm{N}^{*}$, and an increase in the concentration $\mathrm{A}^{\cdot}$ of phytoplankton (in mineral nutrient units) as increased nutrient enrichment leads to the establishment of new trophic levels at the top of the food chain. In the hypothetical situation of Fig. 1, the algal growth rate becomes saturated at a degree of nutrient enrichment between the values where Trophic Level 8 and Trophic Level 9 become established. Once algal growth rate is saturated, further nutrient enrich- 
Frame 3. Closed system. Equilibrium solutions for the food web of Fig. 2 when all populations are established and no growth rates are saturated

Assuming that the copepods have equal preference for large algae and for protozoa, adoption of the formalisms in Frames 1 and 2 gives the following equilibria when all populations have established themselves and no growth rates have reached saturation:

$$
\begin{array}{ll}
\text { Independent of } \mathrm{N}_{\mathrm{o}}: & \\
\text { Copepods: } & \mathrm{C}^{\cdot}=\left(\beta_{\mathrm{F}} \alpha_{\mathrm{F}}\right)^{-1} \delta_{\mathrm{F}} \\
\text { Protozoa: } & \mathrm{P}^{\cdot}=\alpha_{\mathrm{P}}{ }^{-1}\left\{\alpha_{\mathrm{A} 1} \alpha_{\mathrm{A} 2}{ }^{-1}\left[\delta_{\mathrm{A} 2}+\alpha_{C}\left(\beta_{\mathrm{F}} \alpha_{\mathrm{F}}\right)^{-1} \delta_{F}\right]-\delta_{\mathrm{A} 1}\right\} \\
\text { Small phytoplankton: } & \mathrm{A}_{\mathrm{i}}=\left(\beta_{\mathrm{P}} \alpha_{\mathrm{P}}\right)^{-1}\left[\delta_{\mathrm{P}}+\alpha_{\mathrm{C}}\left(\beta_{\mathrm{F}} \alpha_{\mathrm{F}}\right)^{-1} \delta_{\mathrm{F}}\right] \\
\text { Free mineral nutrients: } \mathrm{N}^{*}=\alpha_{\mathrm{A} 2}{ }^{-1}\left[\delta_{\mathrm{A} 2}+\alpha_{C}\left(\beta_{\mathrm{F}} \alpha_{\mathrm{F}}\right)^{-1} \delta_{\mathrm{F}}\right]
\end{array}
$$

Linearly increasing with $\mathrm{N}_{\mathrm{o}}$ :

Fish:

$$
\begin{array}{ll}
\text { Fish: } & F^{*}=\left[1+\left(\beta_{C} \alpha_{C}\right)^{-1} \alpha_{F}\right]^{-1}\left[N_{O}-N^{*}-A_{i}-C^{*}-\left(\beta_{C} \alpha_{C}\right)^{-1} \delta_{C}\right] \\
\text { Large phytoplankton: } & A_{i}=\left(\beta_{C} \alpha_{C}\right)^{-1} \alpha_{F}\left[1+\left(\beta_{C} \alpha_{C}\right)^{-1} \alpha_{F}\right]^{-1}\left[N_{O}-N^{*}-A_{i}-C^{*}+\delta_{C} / \alpha_{F}\right]-P \cdot
\end{array}
$$

Table 1 Symbols and numerical values of parameters

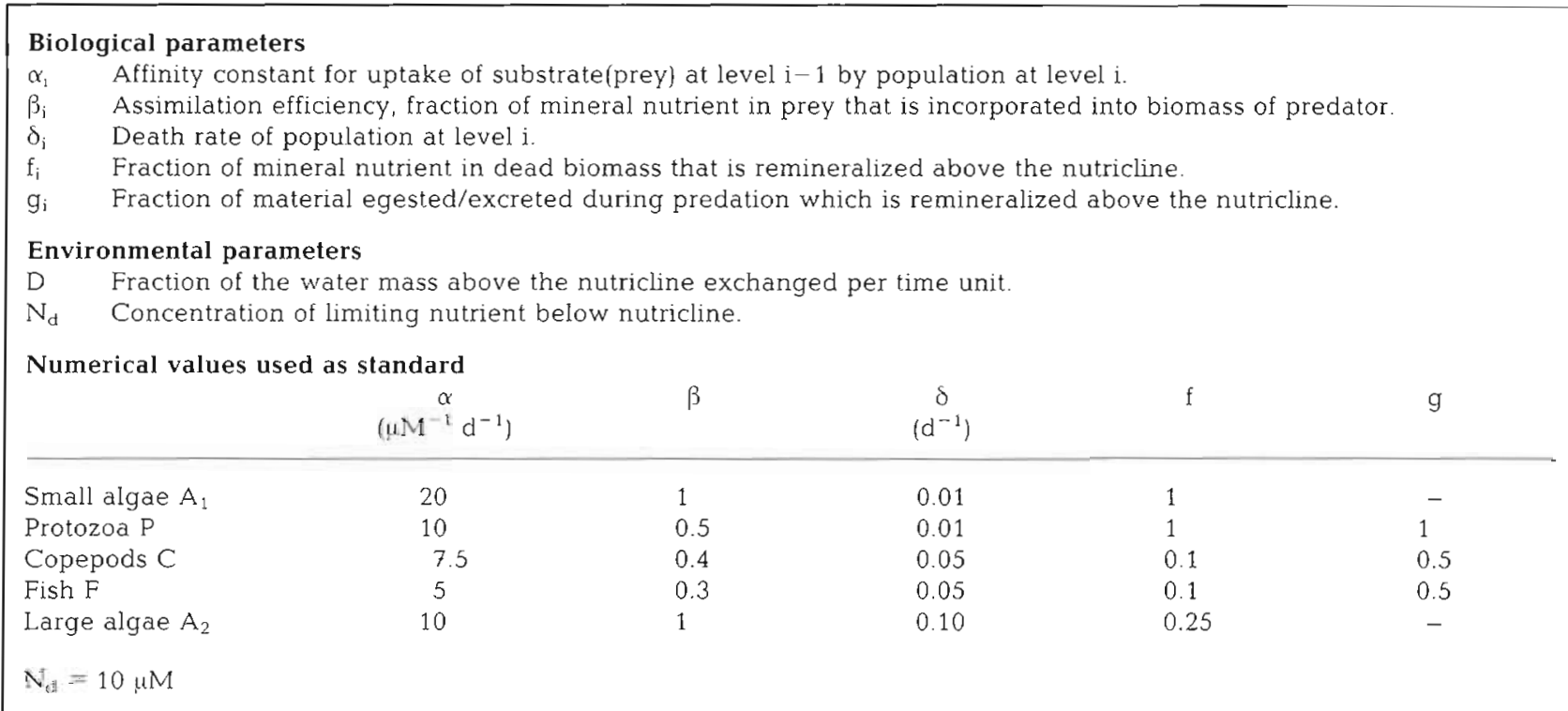

ment will lead only to an increase in the concentration of free mineral nutrient $N^{*}$, which then easily reaches measurable levels.

Three important features emerge from this analysis: (1) Characteristic 'transition points' exist for the degree of nutrient enrichment. At such 'transition points' the effect of further increase in nutrient enrichment on the equilibrium of the system will change. These transition points are caused either by the establishment of a new population, or by the attainment of maximum growth rate of one of the existing population. (2) Dependent upon food web structure, nutrient enrichment may influence both biomass and growth rate of the phytoplankton. (3) Length of the linear food chain will gener- ally increase with increasing enrichment (provided seed populations exist in the environment).

As a digression, some aspects of the question of light limitation versus nutrient limitation may be addressed within this framework. Assuming the only direct effect of light to be on the maximum algal growth rate, i.e. on the parameter $\mu^{m}$, the effect of low light may be deduced from Fig. 1. By shifting downwards the concentration of free mineral nutrient for which algal growth rate becomes saturated $\left(N_{C}{ }^{\prime}\right.$ in Fig, 1), low light levels will control the maximum length attainable for the food chain (which will contain an odd number of predators). For enrichments higher than the transition point ( $\mathrm{N}_{\mathrm{oc}}$ in Fig. 1) where this occurs, the phytoplank- 


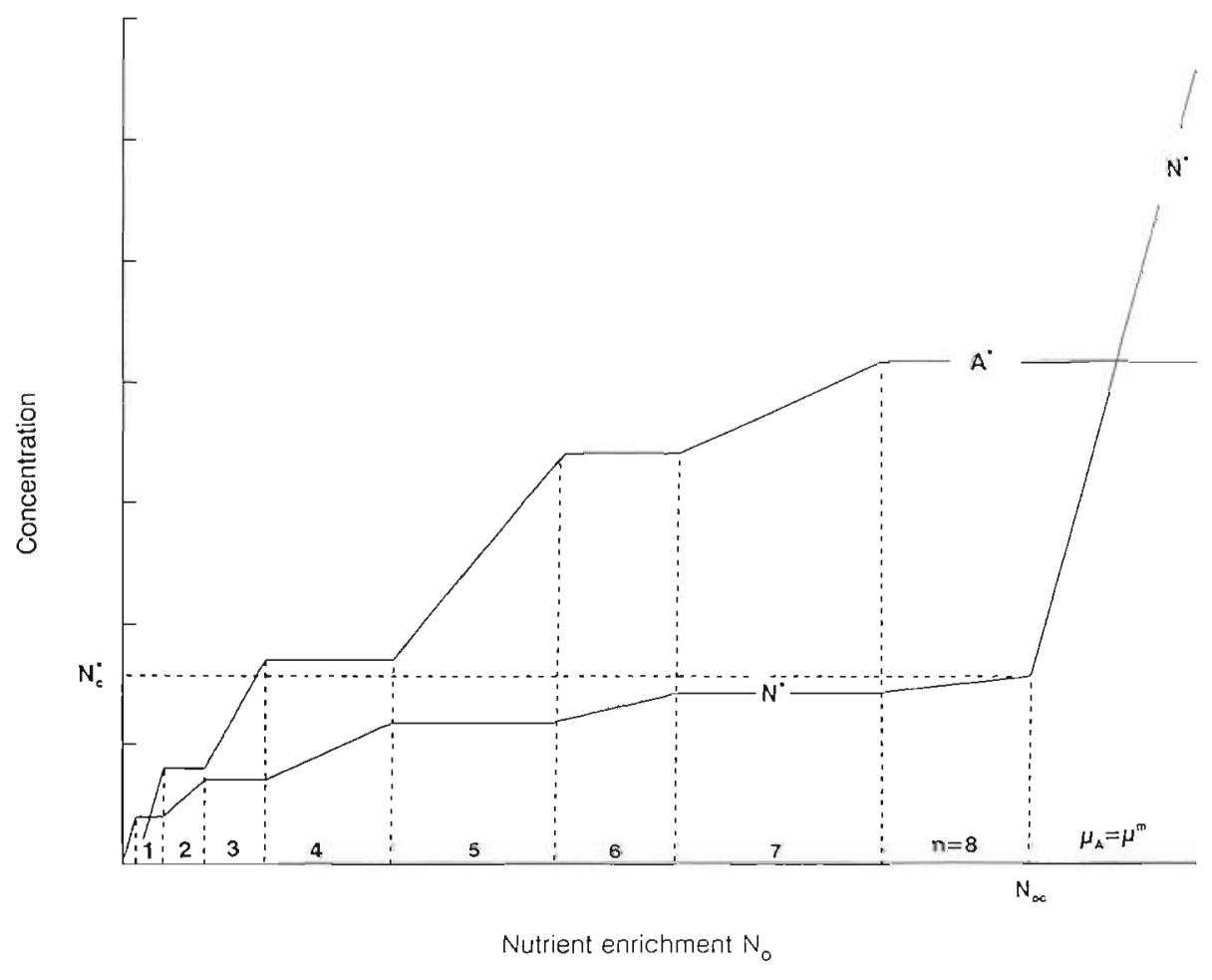

Fig. 1 Closed system, linear food chain. Effect of nutrient enrichment $\left(N_{0}\right)$ on the number (n) of trophic levels, and on the equilibrium concentrations of free mineral nutrients $\left(\mathrm{N}^{*}\right)$ and phytoplankton $\left(\mathrm{A}^{*}\right)$ in a linear food chain of the type described in Frame 1. At distinctive values of nutrient enrichment, indicated by dotted lines, new trophic levels are established at the top of the food chain. Depending upon whether the number of trophic levels is odd or even, either algal biomass (A") or algal growth rate (through $\mathrm{N}^{*}$ ) increases. This pattern continues for increasing $N_{0}$ until the growth rate of one of the populations in the chain is saturated. In this hypothetical example, saturation of phytoplankton growth rate is assumed to occur for the value of free mineral nutrient indicated as $\mathrm{N}_{c}^{*}$ Assuming the direct effect of low light to be a decreased maximum growth rate ( $\mu^{\mathrm{m}}$ ) for the phytoplankton, a lowered light intensity would shift $\mathrm{N}_{c}^{*}$ downwards, and the corresponding value for nutrient enrichment, $\mathrm{N}_{o c}$, to the left implying a shorter maximum length of the food chain. If $N_{o c}$ becomes smaller than the actual value of $N_{0}$, it would then be reasonable to use the term 'light limitation' of phytoplankton growth rate

ton will grow at maximum growth rate attainable for the light given, and the phytoplankton may reasonably be termed 'light limited'. Since low temperature is another environmental factor that may lead to low values of $\mu^{\mathrm{m}}$, similar comments should be applicable to effects expected in cold waters.

The analysis above has not given any consideration to the question of stability of the equilibria. Since we are dealing with a chain of predator-prey relationships, one might suspect the systems to be unstable. However, as shown in Frame 4 for the special case of a 2 step food chain, nutrient recycling acts as a negative feedback, with a stabilizing influence. This feedback control disappears when algal growth rate reaches $\mu^{\mathrm{m}}$. For values of $\mathrm{N}_{\mathrm{o}}$ beyond the transition point where $\mu^{\mathrm{m}}$ is reached, persistent oscillations therefore occur. Other mechanisms affecting the feedback, such as delays in the recycling process, are also known to lead to instabilities (Hutchinson 1948).

\section{Large and small phytoplankton}

The importance of phytoplankton cell size as a parameter closely linked to the mechanisms regulating planktonic ecosystems is widely recognized (e.g. Parsons et al. 1977). One aspect of this problem is why so many different phytoplankton species can coexist in an apparently very homogenous environment, i.e. Hutchinson's paradox (Hutchinson 1961). One explanation to this paradox is predation (Jost et al. 1973a,b). The background for this is easily understandable in light of the previous discussion. It was shown (Fig. 1) that with a predator (or an odd number of predators in a linear chain) on an algal population $\left(A_{1}\right)$, an increase in the nutrient enrichment $N_{0}$ will lead to an increased concentration of free mineral nutrient $N \cdot$. For sufficiently high concentrations of the free mineral nutrient, this may lead to a growth rate balancing the loss rates for another algal population $\left(\mathrm{A}_{2}\right)$, and thereby allow the 
Frame 4. Closed system. Demonstration of the stabilizing effect of recycling for the speciai case of one population of phytoplankton and one type of zooplankton $(n=2)$
For unsaturated growth rates, the equations of Frame 1 become:
$\mathrm{dA} / \mathrm{dt}=\alpha_{\mathrm{A}} \mathrm{NA}-\delta_{\mathrm{A}} \mathrm{A}-\alpha_{\mathrm{Z}} \mathrm{AZ}$
$\mathrm{dZ} / \mathrm{dt}=\beta_{Z} \alpha_{Z} \mathrm{AZ}-\delta_{Z} Z$
$N_{0}=N+A+Z$
where $A_{1} Z$ and $N$ refer to algae, zooplankton, and free mineral nutrients respectively.
Using Eq. (4.3), $N$ can be replaced in Eq. (4.1) to give:
$\mathrm{dA} / \mathrm{dt}=\alpha_{\mathrm{A}}\left(\mathrm{N}_{\mathrm{o}}-\delta_{\mathrm{A}} / \alpha_{\mathrm{A}}-\mathrm{A}\right) \mathrm{A}-\left(\alpha_{\mathrm{A}}+\alpha_{Z}\right) \mathrm{AZ}$
Eqs (4.4) and (4.2) are formally equivalent to a set of Volterra equations with self-limitation of the prey (A). The solution to this set of equations is a dampened oscillation in A and Z (e.g. Maynard Smith 1974).
If, however, growth rate of the algae is saturated, Eq. (4.1) becomes:
$\mathrm{dA} / \mathrm{dt}=\left(\mu_{\mathrm{A}}^{\mathrm{m}}-\delta_{\mathrm{A}}\right) \mathrm{A}-\alpha_{\mathrm{Z}} \mathrm{AZ}$
which, when combined with Eq. (4.2) has solutions with persistent oscillations.

establishment of this population. The widening of the food web by introduction of another algal species is therefore easily explainable and represents no paradox within this framework. The first algal species to establish itself will be the one with the lowest value for $\delta \mathrm{K} /$ $\mu^{\mathrm{m}}$. An assimilation efficiency $\beta=1$ is here assumed for phytoplankton, and the affinity constant $\alpha$ is substituted by the initial slope $\mu^{\mathrm{m}} / \mathrm{K}$ of a Monod-type growth curve (Monod 1942), where $\mu^{\mathrm{m}}$ is the maximum growth rate obtained at saturating concentrations of free mineral nutrient, and $K$ is the concentration for which a growth rate of $\mu^{m} / 2$ is obtained. Data concerning the variation of $\mu^{\mathrm{m}}$ and/or $\mathrm{K}$ have been reviewed by several authors (Laws 1975, Malone 1980, Smith \& Kalff 1982 , Raven 1988, Garside \& Glover in press). The general conclusion seems to be that the value of $K$ increases with increasing cell size of the phytoplankton. Within the separate groups of diatoms and dinoflagellates, small species seem to have larger values for $\mu^{\mathrm{m}}$ than large ones (Banse 1982). In the data reviewed by Garside \& Glover (in press), species with cell diameters in the range 2 to $4 \mu \mathrm{m}$ have higher $\mu^{\mathrm{m}}$ than those with cells in the range 8 to $85 \mu \mathrm{m}$. Chlorophyll-specific carbon fixation at optimal light conditions seem to be higher in nano- than in net-plankton (Malone 1980).

The latter author summarized 3 conspicuous trends in data for phytoplankton sedimentation. (1) flagellates are capable of controlling their position in the water column; (2) exponentially growing cells have low sinking rates; and (3) small cells or colonies tend to have lower sinking rates than larger cells or colonies. When, in the open system, we include sedimentation loss, this will tend to give larger phytoplankton species a higher value for $\delta$. As a general trend, one could therefore expect small phytoplankton to have a low value for the compound parameter $\delta \mathrm{K} / \mu^{\mathrm{m}}$, and therefore be the first to establish themselves at low levels of nutrient enrichment. Large species with high values of $\delta \mathrm{K} / \mu^{\mathrm{m}}$ will only be established when a long food chain and a high growth rate of the small phytoplankton already exist. The growth rates of the 2 algal populations, once both of them are established, are of course dependent upon parameter values of the model. With increasing nutrient enrichment, the small phytoplankton $\left\{A_{1}\right\}$ may reach their maximum growth rate, in which case free nutrient concentration will increase rapidly (as in Fig. 1) to a level where the large phytoplankton may establish themselves. If maximum growth rate of $A_{1}$ is not reached before establishment of $A_{2}$, the ratio of the growth rates will be the ratio between their affinity constants $\alpha$. According to the discussion above, large phytoplankton would thus have a lower specific growth rate than small phytoplankton.

\section{A simple closed food web}

As a first approximation to something that resembles a modern notion of a marine planktonic food web, we will use the 5-membered food web shown in Fig. 2. In this, small pico- and nano-sized phytoplankton are preyed upon by protozoans (Goldman \& Caron 1985) which again are grazed by copepods (Sherr et al. 1986). Large phytoplankton, typically diatoms, may directly be fed upon by the copepods, which again serve as food for planktivorous fish. The general principles of how nutrient enrichment will affect the equilibrium of this system may be derived from the previous analysis. 


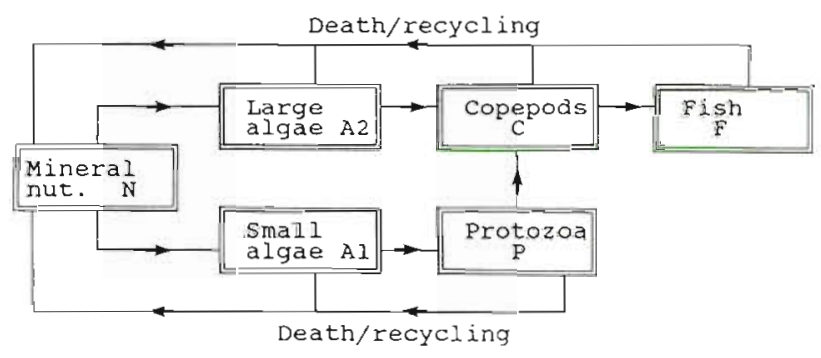

Fig. 2. Idealized pelagic food web based on 2 size categories of phytoplankton

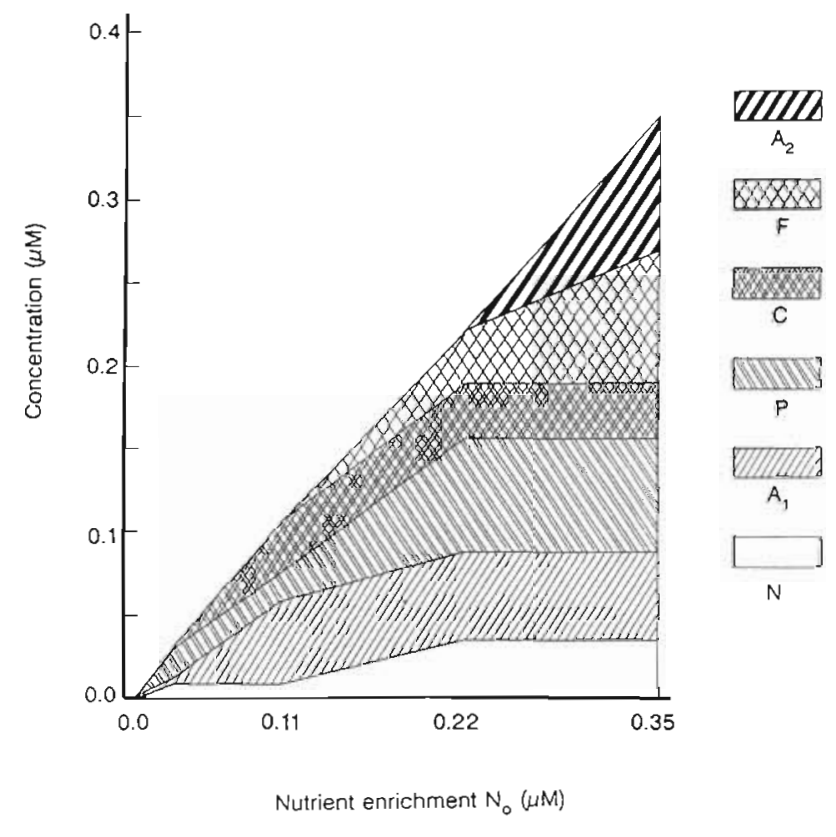

Fig. 3. Closed system. The effect of nutrient enrichment on equilibrium food web structure for the food web shown in Fig. 2 with biological parameters chosen as in Table 1. The width of each shaded area represents the amount of mineral nutrient in the biomass at one trophic level. Upper border line thus corresponds to nutrient enrichment $N_{0}$

The linear food chain 'small phytoplankton - protozoans - copepods - fish' will develop until the large phytoplankton can establish themselves (Fig. 3). This does not occur until the concentration of free mineral nutrient is sufficient to allow a growth rate of large phytoplankton that balances both algal death rate and predation rate from copepods. With a large difference between the 2 algal types in the value of $\delta \mathrm{K} / \mu^{\mathrm{m}}$, one would not expect $A_{2}$ to become established unless nutrient enrichment is sufficient to support a long food chain with $A_{1}$ at the bottom and fish at the top. With a long food chain, a specific growth rate of $A_{1}$ at, or close to, maximum would be expected. As shown by Eqs. (3.5) and (3.6) in Frame 3, further increase in nutrient enrichment will lead to increase in the equilibrium concentrations of large phytoplankton and fish, while the growth rate and biomass of small phytoplankton remain constant (Eqs. 3.3 and 3.4). In the vicinity of the point of establishment of $A_{2}$, the phytoplankton community is thus dominated by small, rapidly growing phytoplankton.

The specific values of $N_{0}$ for which the different populations establish themselves is a function of the biological parameters $(\alpha-, \beta$ - and $\delta$-values). The parameter values chosen (Table 1) produce extremely oligotrophic equilibrium situations (Figs. 3 and 4). Lowering the values for the $\alpha$-or increasing the values for the $\delta$-parameters would be examples of parameter changes that leads to less extreme oligotrophy at equilibrium.

\section{Sedimentation/mixing: the equilibrium position $\left(\mathrm{N}_{0}^{*}\right)$ for nutrient enrichment}

So far, we have assumed the system to be closed with respect to mineral nutrients, i.e. no nutrients were lost or imported. All production has therefore been 'old' or 'regenerated' production in the sense of Dugdale \& Goering (1967). In a stratified water column, however, one would expect mineral nutrients to be lost from the upper layer by sedimentation, while import to this layer through the nutricline could occur through processes such as turbulent mixing. The system is then no longer closed, and the degree of nutrient enrichment $\mathrm{N}_{0}$ will change with time (Eq. 1.4) until an eventual stable equilibrium value $\mathrm{N}_{\mathrm{o}}$ is reached. This equilibrium value for nutrient enrichment must correspond to a composition of the food web that produces a total loss equilibrating inputs of mineral nutrients. A close coupling thus exists between nutrient inputs, equilibrium structure of the food web and the sedimentation properties of the different groups of organisms (Fig. 4). If sedimentation losses are produced by small phytoplankton or protozoa, the curve for loss rate of mineral nutrients from the populations $\left(\mathrm{L}_{2}\right)$ will increase rapidly even for small values of $N_{0}$. If, however, losses occur due to large organisms only, a large value of $N_{0}$ is required before the food chain has extended to a length where the amount and activity of these large organisms produce a sedimentation loss $\left(\mathrm{L}_{1}\right)$ that compensates a given rate of nutrient input $\left(\mathrm{I}_{1}\right.$ or $\left.\mathrm{I}_{2}\right)$. In the formulation we have chosen here, input of mineral nutrients to the layer above the nutricline is assumed to be proportional to the difference in concentration of free mineral nutrients below $\left(\mathrm{N}_{\mathrm{d}}\right)$ and above $(\mathrm{N})$ the nutricline. The proportionality constant (D) expresses the fraction of the water mass above the nutricline exchanged per day. $D$ is thus a parameter containing the ratio between the rate of the exchange processes and the depth of the 


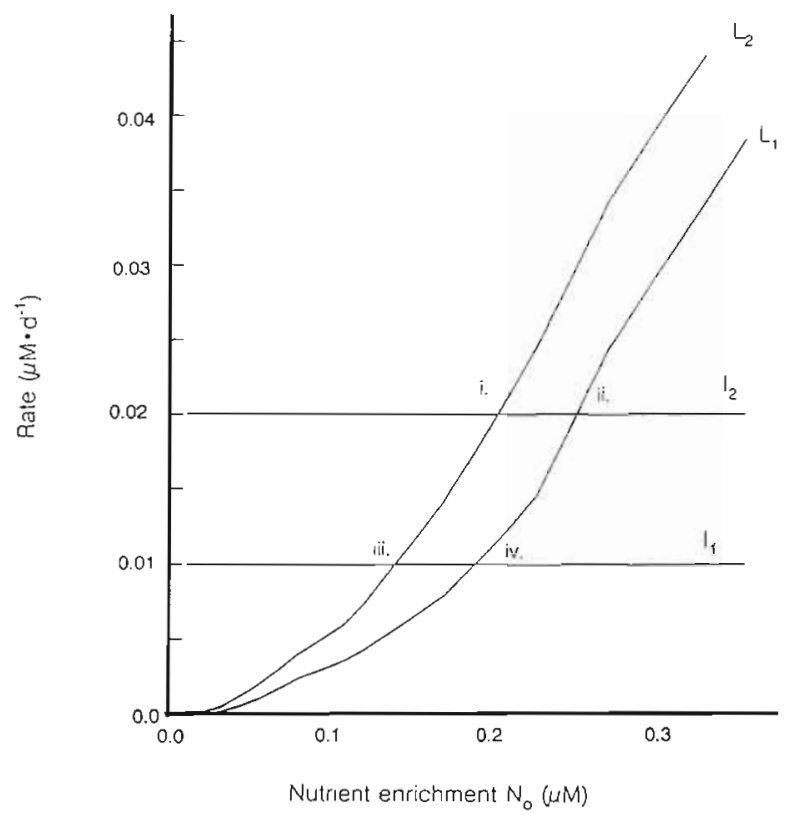

Fig. 4. Equilibrium condition of open system. Curves for nutrient input due to mixing (left side of Eq. 2.2) are shown for: $\left(I_{1}\right) \mathrm{D}=0.001 \mathrm{~d}^{-1}$, and $\left(I_{2}\right) 0.002 \mathrm{~d}^{-1}$ Curves for loss due to sedimentation (right side of Eq. 2.2) are shown for: $\left(L_{1}\right)$ the standard set of parameters given in Table $1_{1}$ and $\left(L_{2}\right)$ with the 3 parameters $f_{A 1}, f_{P}$, and $g_{P}$ decreased from 1 to 0.5 to demonstrate the effect of increased sedimentation from small organisms. For the parameter values used, effects of $\mathrm{D}$ on curves $\mathrm{L}_{1}$ and $\mathrm{L}_{2}$ were minimal, and are not shown. From the position of the 4 alternative crossing points ( $i, i i$, iii and $i v)$, it is seen how a large value of $D$ and a low production of sedimenting material from small organisms will produce a high value for $\mathrm{N}_{0}$. (ii), while a low value for $D$ and a high production of sedimenting material from small organisms will produce a low $\mathrm{N}_{\mathrm{o}}^{*}$ (iii)

nutricline. In this formulation, nutrient input rate at equilibrium $\left(=\mathrm{D} \cdot\left(\mathrm{N}_{\mathrm{d}}-\mathrm{N}^{\bullet}\right)\right)$ varies with food chain structure only through the value of $N^{*}$. Since $N^{*}<<N_{d}$, input rate is therefore nearly independent of $N_{0}$. With the parameters chosen as standard in Table $1\left(\mathrm{f}_{\mathrm{A}_{1}}=1\right.$ and $f_{p}=1$ ), there is no sedimentation loss due to small phytoplankton $\left(\mathrm{A}_{1}\right)$ or protozoa $(\mathrm{P})$. These 2 populations will therefore establish themselves even at values of $D$ close to zero (Fig. 5). For larger values of D, copepods and fish become established. Free nutrients $\mathrm{N}^{*}$, and thereby growth rate of small phytoplankton, then increase, until finally large phytoplankton become established for sufficiently high values of $\mathrm{D}$. The upper border line of the shaded areas in Fig. 5 indicates the value of the equilibrium nutrient enrichment $\mathrm{N}_{\mathrm{o}}^{*}$ as a function of the mixing coefficient $\mathrm{D}$. The rather low $\mathrm{N}_{\mathrm{o}}^{\circ}$ values obtained in Fig. 5 would shift to higher values if e.g. the values of the $\alpha$-parameters are decreased or the values of the $\delta$-parameters are increased.

For parameter values that produce large increases in sedimentation loss for small increases in $A_{2}$ (e.g. large
$\delta_{A 2}$ or small $f_{A 2}$, the increase in equilibrium concentration $\mathrm{A}_{2}$ of large phytoplankton accompanying an increase in $D$ would be small. As a result, there may be an extensive range of values for $D$ for which the phytoplankton community would be dominated by small,

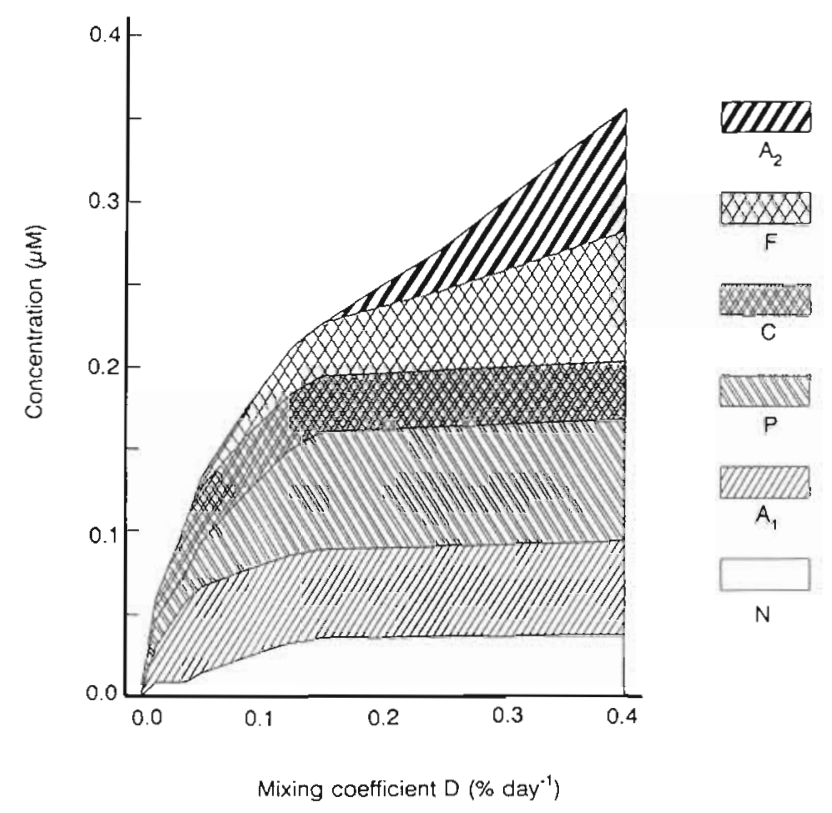

Fig. 5. Open system. Effect of mixing coefficient (D) on food web structure. Shading as in Fig. 3. The upper border line of the shaded areas now represents equilibrium nutrient enrichment $\left(\mathrm{N}_{0}^{*}\right)$

rapidly growing phytoplankton $A_{1}$. For sufficiently large values of $\mathrm{D}$, however, the food web will be dominated by the transport through the 'traditional' food chain 'large phytoplankton - copepods - fish'.

Since, in this model, there is one more trophic level between the small phytoplankton and the top predator (fish) than there is between the large phytoplankton and fish, one would expect changes at the top predator level to have opposite effects on biomass of the 2 populations. Effects on growth rate must, however, be in the same direction for both populations since they share a common limiting substrate $(\mathrm{N})$. These top-down controlling effects on the algal community are demonstrated in Fig. 6 a for a change in the affinity constant $\alpha_{F}$ of fish preying on copepods. Large values of $\alpha_{F}$ will shift the equilibrium of the system towards a dominance of large phytoplankton and a low degree of nutrient enrichment (low values for $N_{0}^{*}$ ). Similarly, one may demonstrate a bottom-up control of the system. This is visualized in Fig. $6 \mathrm{~b}$ as the effects of changing the affinity constant $\alpha_{A 2}$ of large phytoplankton for mineral nutrient. Large values of $\alpha_{\mathrm{A} 2}$ will shift the biomass dominance in the phytoplankton community towards $A_{2}$, while $N^{*}$, and therefore growth rates of $A_{1}$, decreases. 

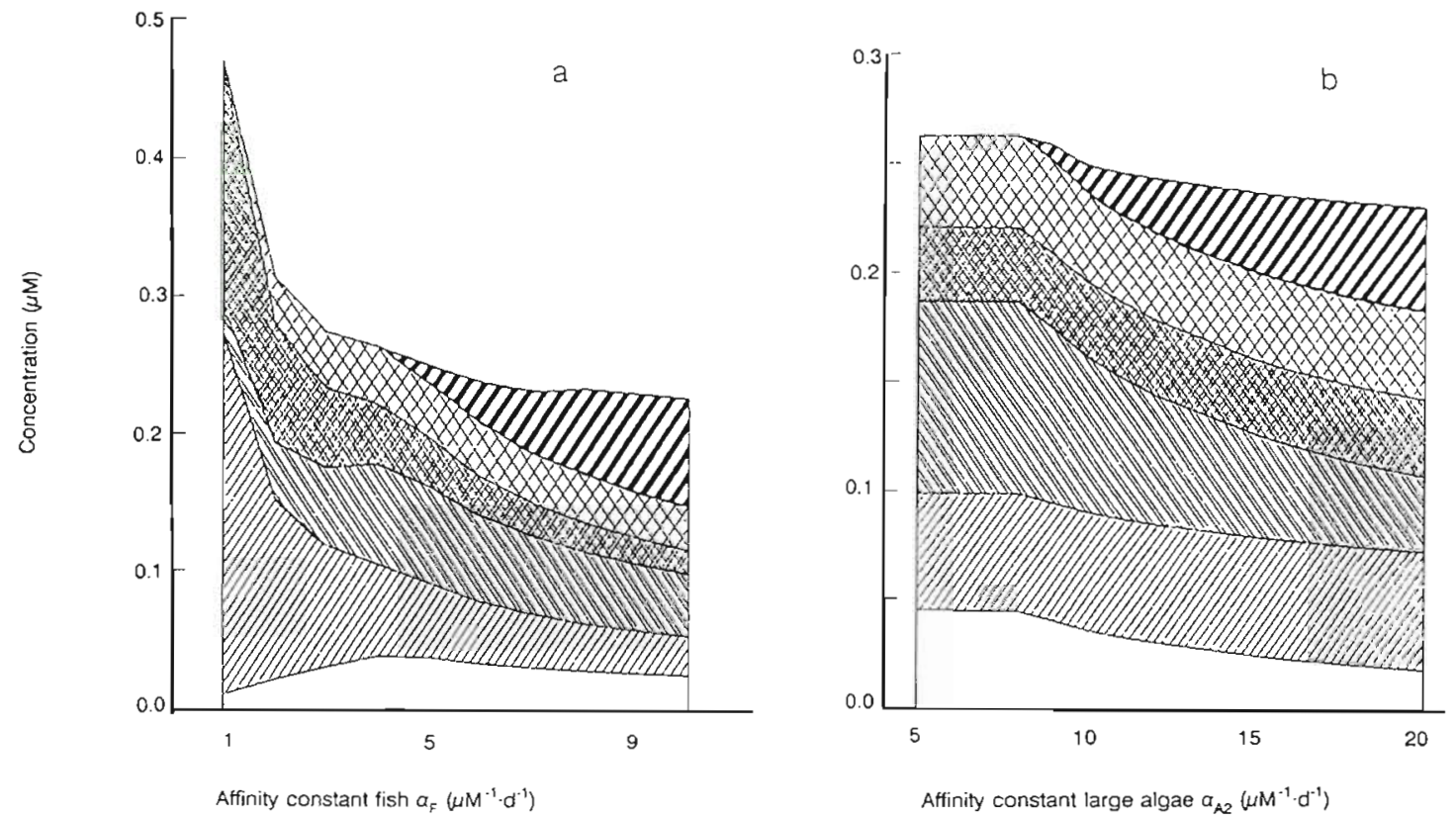

Fig. 6. Open system. Effect of (a) affinity constant $\left(\alpha_{F}\right)$ of fish predation, and (b) affinity constant $\left(\alpha_{A 2}\right)$ of large phytoplankton on food web structure. Shading as in Fig. 3. Upper border line represents equilibrium nutrient enrichment $N_{o}^{*}$

The analysis given here does not allow a discussion of the stability properties of the steady states. Using a slightly more elaborated model (not shown here), with Monod-type growth responses, numerical solutions to the differential equations were obtained using a fourth order Runge-Kutta technique. This indicated that large values of $\mathrm{D}$ tended to destabilize the system. In accordance with traditional analysis of predator-prey systems (Rosenzweig \& MacArthur 1963), stability of this model was enhanced by the addition of limits for the prey concentrations below which predation ceased.

\section{DISCUSSION}

The purpose of the idealized models constructed here has been to provide a framework within which the concept of 'control' of the phytoplankton community in pelagic ecosystems could be meaningfully explored. A general understanding of this 'control' is not easily gained from knowledge of the biology of the participating groups of organisms alone, nor is it necessarily gained from complex models based on extensive realism in biological detail. The analysis presented here is restricted to the equilibrium situation. This is, of course, too coarse an approximation to give a satisfactory description of many real systems. Natural systems are subject to both periodic and stochastic forces such as diurnal light cycles, mixing by strong winds, migration by larger organisms etc. There are also a host of biological mechanisms and interactions of obvious importance not included here. As one example of this, the model is based on one common limiting mineral nutrient for all groups of phytoplankton. Effects such as exclusion of diatoms due to lack of silicate have therefore not been discussed. Against the multitude of possible objections concerning a low level of realism in the models analyzed, we will argue that a thorough understanding of the equilibria of highly idealized models represents a kind of minimum requirement for the development of a conceptual framework within which 'understanding' of real systems could be hoped for. It would also seem that the prospect of gaining understanding from more complex, and therefore presumably more realistic, simulation models, would be improved if the behavior of idealized models is thoroughly comprehended.

The importance of size relationships in the planktonic food web is well demonstrated (e.g. Sheldon et al. 1972), and much of the essence of the proposed model is embedded in size relationships: (1) in a tendency for small phytoplankton to have a low value of the compound parameter $\delta \mathrm{K} / \mu^{\mathrm{m}}$, , (2) in the possibility for these small organisms to form the basis of a food chain of predator organisms which will include several steps before the top predators contribute significantly to sedimentation losses, and (3) in a rapid increase in sedimentation loss once large phytoplankton are established. At the same time, the building up of a long food chain originating from the small phytoplankters provides a mechanism leading to increasing concentrations of free mineral nutrients. The summary effect of this would be a high growth rate of the small phytoplankton, and the potential establishment of larger 
phytoplankton with higher transition points for establishment. The establishment of these new algal species growing at suboptimal rates would impede further increase in the concentration of free mineral nutrients, an effect which, depending on parameter values (Eq. 3.4), may occur before measurable concentrations of free mineral nutrients are reached. If the large phytoplankton produce large amount of sedimenting material, there will be an extensive range of values for the mixing parameter $\mathrm{D}$ where the slowly growing population of large phytoplankton constitutes a minority in the phytoplankton community. Without methods of measurement carefully designed to look for differences in growth rate, the community as a whole may therefore appear to grow fast.

Although the analysis of a linear food chain suggested that increasing nutrient enrichment should lead to increasing length of the food chain, the inclusion of different algal types provided a demonstration of how a shorter food chain based on large phytoplankton could become dominating as nutrient input was increased. This principle conforms in many aspects to the relationship between food chain structure and type of marine environment described by Ryther (1969). As summarized in Table 2, his description emphasizes the shift from small phytoplankton entering at the bottom of a long food chain in oceanic environments, to an increasing dominance of large phytoplankton entering the predator chain at higher levels in coastal and upwelling areas. References to experimental work supporting the notion that strong vertical mixing or high nutrient inputs are coupled to a high proportion of diatoms, while low mixing favors a community dominated by flagellates, may also be found in Malone (1980) and Harrison \& Turpin (1982).

An example of a system dominated by small phytoplankton growing at rapid specific growth rates has been described by Laws et al. (1984). In their investigation off Hawaii, $60 \%$ of the chlorophyll passed a $3 \mu \mathrm{m}$ Nuclepore filter and specific growth rate estimates of 1 to $2 \mathrm{~d}^{-1}$ were close to expected maximum values. Both these and other authors (e.g. Goldman et al. 1979, Jackson 1980) suggest that predation and recycling by microzooplankton is the mechanism underlying rapid algal growth. Such an explanation conforms to the model presented here, but lacks an explanation of how a balance is reached combining rapid growth with unmeasurable concentrations of limiting nutrient. In the model presented here, this occurs if the concentration of free mineral nutrient at which the large algae establish themselves (Eq. 3.4) is below detection limit.

Although the analysis presented here is based entirely on steady state relationships, some conclusions may be drawn concerning non-steady state behavior. One of the more interesting is how the system responds to pulses of nutrient inputs. Since the small phytoplankton are growing at, or near, maximum growth rates, the primary effect of a pulse in nutrient input would be expected to cause a subsequent peak in the abundance of large phytoplankton. This would be in agreement with the statement of Malone (1980) that pulses in the biomass of netplankton diatoms ... tend to be greater in amplitude than pulses in nanoplankton biomass'. Even if the small phytoplankton species should have a large physiological capacity for luxury nutrient consumption (Sakshaug \& Olsen 1986), their possibility of taking advantage of this will be marginal when they are already growing at a rate close to maximum.

Although we have not made any detailed study of the stability of the equilibrium, the model may have some relevance to the stability versus complexity discussion (e.g. McNaughton 1988). In the model presented here, nutrient enrichment or increase in the mixing coeffi-

Table 2. Pelagic food chains suggested by Ryther (1969) as typical of different marine environments (version adapted from Parsons et al. 1977)

\begin{tabular}{|c|c|c|c|c|c|c|c|}
\hline \multirow{2}{*}{$\begin{array}{l}\text { Environment } \\
\text { Oceanic: }\end{array}$} & \multicolumn{7}{|c|}{ Food chain } \\
\hline & $\begin{array}{l}\text { Nanoplankton } \\
\text { (small flagellates) }\end{array}$ & $\rightarrow$ & $\begin{array}{l}\text { Microzooplankton } \\
\text { (protozoa) }\end{array}$ & $\rightarrow$ & $\begin{array}{l}\text { Macrozooplankton } \\
\text { (crustacean zoopl.) }\end{array}$ & $\rightarrow$ & $\begin{array}{l}\text { Megazooplankton } \\
\text { (e.g. chaetognaths } \\
\text { \& euphausiids) }\end{array}$ \\
\hline$\rightarrow$ & $\begin{array}{l}\text { Planktivores } \\
\text { (e.g. lantern fish } \\
\text { \& saury) }\end{array}$ & $\rightarrow$ & $\begin{array}{l}\text { Piscivores } \\
\text { (e.g. squid, } \\
\text { salmon \& tuna) }\end{array}$ & & & & \\
\hline Coastal: & $\begin{array}{l}\text { Micro- and nano- } \\
\text { phytoplankton }\end{array}$ & $\rightarrow$ & Macrozooplankton & $\rightarrow$ & Planktivores & $\rightarrow$ & Piscivores \\
\hline Upwelling: & $\begin{array}{l}\text { Macro-phytoplankton } \\
\text { (Large diatoms and } \\
\text { dinoflagellates) }\end{array}$ & $\rightarrow$ & $\begin{array}{l}\text { Planktivores } \\
\text { (e.g. anchovy) } \\
\text { or } \\
\text { (megazooplankton } \\
\text { e.g. Euphausia sup }\end{array}$ & $\begin{array}{l}\rightarrow \\
\text { (ba) }\end{array}$ & $\begin{array}{l}\text { Planktivores } \\
\text { (e.g. whales) }\end{array}$ & & \\
\hline
\end{tabular}


cient $\mathrm{D}$ leads to increased system complexity as new populations are established. As indicated in Frame 4, saturation of algal growth rate is expected to destabilize the system. Increasing the complexity by increasing new 'larger' phytoplankton species with suboptimal growth rates would therefore be expected to stabilize the equilibrium. If, however, the increase in complexity occurs through a lengthening of the food chain, as in Fig. 1, the resulting saturation of algal growth rate would be expected to destabilize the equilibrium. From this, no simple relationship would be expected between a general 'complexity' and stability.

Bacterial production is intimately related to the mechanisms controlling flows of carbon and mineral nutrient between the microbial components of the food web (Thingstad \& Pengerud 1985, Pengerud et al. 1987, Sherr et al. 1988). The model presented here does not include bacteria. The concept developed could, however, have important implications for the possible models of how dissolved organic substrates for bacterial growth are produced. A picture where a large fraction of the phytoplankton grow at near-maximum growth rates seems difficult to reconcile with an assumption of photosynthetic products being excreted as a response to mineral nutrient limitation (Azam et al. 1983, Bratbak \& Thingstad 1985).

Our analysis highlights the necessity of considering the whole system when 'regulating factors' in an ecosystem are sought. With a conceptual base in Liebig's law of the minimum, many ecological discussions have as an explicit or implicit assumption that a single 'controlling', 'limiting' or 'minimum' 'factor', exists. The ecological insight sought is indeed often to identify this 'factor'. In apparent opposition to this, the mathematical analysis of such systems produces an impression of strong interdependence between all components. Any change in almost any feature will spread through the system to produce transient and/or permanent changes. It is, however, also obvious that shortage in mineral nutrient plays a key role by influencing both biomass and growth rate of the populations. To some extent, this dilemma can be solved by considering the parallel found in traditional chemostat theory (e.g. Veldkamp 1976). Here the specific growth rate of the organism in the chemostat must equal the dilution rate. Dilution rate, which is the ratio between pump rate and culture volume, thus controls growth rate. This control is, however, indirect. What the organisms 'see' is the suboptimal concentration of the substrate. This substrate is adequately termed the 'limiting' substrate. In this context it is obviously confusing to extend the term 'limiting factor' to include pump rate or culture volume. In the description used here for the pelagic system, it would seem logical to use the same distinction. Phytoplankton could then be 'limited' by nutrients, light or temperature, but the degree of nutrient limitation would be 'controlled' by a multitude of factors acting indirectly through the many interactions of the system. One should, however, be aware that this terminology connects the term 'limiting factor' to the type of model used. Exchanging our Monod-type models with Droop-type descriptions (Droop 1974), the explicit dependency of growth rate would be on the internal, not on the external, concentration of the mineral nutrient. At a physiological level, the distinction between a 'controlling' and a 'limiting' factor may therefore be less obvious.

Using this terminology we would say that the proposed model demonstrates how the degree of nutrient limitation of phytoplankton is strongly 'controlled' by the rest of the system. Part of this control of the degree of limitation may reasonably be described as 'predator control', but it is also evident from the analyses presented that there is an extremely important component, which, in the same line of loose terminology, could be called a 'sedimentation control'. One could also easily argue for a 'competitor control'. With careful use, this terminology may retain the 'limiting factor' concept as a logically meaningful construction, as long as the compatibility of this concept with the existence of a multitude of 'controlling factors' modifying the effect of limitation is clearly recognized. Rephrased, one could say that the limitation of algal growth rate in our model from 'below' through nutrient limitation, is controlled from 'above' through predation/recycling, 'sideways' from competition, and from the 'outside' through the physical mixing processes. Again, however, it would seem futile and potentially confusing to try to assign the control to be exerted strictly from one of these directions in the food web. 'Control' is a property of the system as a whole, and can only be properly understood as such.

Acknowledgements. This work is part of the Norwegian Research Program for Marine Arctic Ecology (Pro Mare). We are indebted to our colleagues within the Program for numerous discussions which have formed the background of this article, and to Drs I. Dundas, T Fenchel, M. Levandowsky, W. Silvert, and H. R. Skjoldal for critical comments on the manuscript.

\section{LITERATURE CITED}

Azam, F., Fenchel, T., Field, J. G., Gray, J. S., Meyer-Reil, L. A., Thingstad, T. F. (1983). The ecological role of watercolumn microbes in the sea. Mar. Ecol. Prog. Ser. 10: $257-263$

Banse, K. (1982). Cell volumes, maximal growth rates of unicellular algae and ciliates, and the role of ciliates in the marine pelagial. Limnol. Oceanogr. 27: 1059-1071

Bratbak, G., Thingstad, T F. (1985). Phytoplankton-bacteria interactions: an apparent paradox? Analysis of a model 
system with both competition and commensalism. Mar Ecol. Prog. Ser. 25: 23-30

Carpenter, S. R., Kitchell, J. F. (1984). Plankton community structure and limnetic primary production. Am. Nat. 124: $159-172$

Carpenter, S. R., Kitchell, J. F., Hodgson, J. R. (1985). Cascading trophic interactions and lake productivity. BioSci. 35: $634-639$

Droop, M. R. (1974). The nutrient status of algal cells in continuous culture. J. mar. biol. Ass. U. K. 54: 825-855

Dugdale, R. C. (1967). Nutrient limitation in the sea: dynamics, identification, and significance. Limnol. Oceanogr. 12: 685-695

Dugdale, R. C., Goering, J. J. (1967). Uptake of new and regenerated forms of nitrogen in primary productivity. Limnol. Oceanogr. 12: 196-206

Eppley, R. W., Peterson, B. J. (1979). Particulate organic matter flux and planktonic new production in the deep ocean Nature, Lond. 282: 677-680

Garside, C., Glover, H. F. (in press). Chemoluminescent measurements of nitrate kinetics: I. Thalassiosira pseudonana (clone H3) and neritic assemblages. Limnol. Oceanogr.

Goldman, J. C. (1986). On phytoplankton growth rates and particulate C:N:P ratios at low light. Limnol. Oceanogr. 31: $1358-1363$

Goldman, J. C., Caron, D. A. (1985). Experimental studies on an omnivorous microflagellate: implications for grazing and nutrient regeneration in the marine microbial food chain. Deep Sea Res. 32: 899-915

Goldman, J. C., McCarthy, J. J., Peavey, D. C. (1979). Growth rate influence on the chemical composition of phytoplankton in oceanic waters. Nature, Lond 279: 210-215

Harris, G. P. (1983). Mixed-layer physics and phytoplankton populations: Studies in equilibrium and non-equilibrium ecology. In: Round, F. E., Chapman, D. J. (eds.) Progress in phycological research, Vol. 2. Elsevier Science Publishers, Amsterdam, p. 1-52

Harrison, P. J., Turpin, D. H. (1982). The manipulation of physical, chemical, and biological factors to select species from natural phytoplankton communities. In: Grice, G. D., Reeve, M. R. (eds.) Marine mesocosms. Biological and chemical research in experimental ecosystems. SpringerVerlag, New York, p. 275-289

Hutchinson, G. E. (1948). Circular causal systems in ecology Ann. N. Y. Acad. Sci. 50: 221-246

Hutchinson, G. E. (1961). The paradox of the plankton. Am. Nat. 95: 137-145

Jackson, G. A. (1980). Phytoplankton growth and zooplankton grazing in oligotrophic oceans. Nature, Lond. 284: 439-441

Jost, J. L., Drake, J. F., Fredrickson, A. G., Tsuchiya, H. M (1973a). Interactions of Tetrahymena pyriformis, Escherichia coli, Azotobacter vinelandii, and glucose in a minimal medium. J. Bacteriol. 113: 834-840

Jost, J. L., Drake, J. F., Tsuchiya, H. M., Fredrickson, A. G. (1973b). Microbial food chains and food webs. J. theor. Biol. $41 \quad 461-484$

Lane, P., Levins, R. (1977). The dynamics of aquatic systems 2. The effects of nutrient enrichment on model plankton communities. Limnol. Oceanogr. 22: 454-471

Laws, E. A. (1975). The importance of respiration losses in controlling the size distribution of marine phytoplankton. Ecology 56: 419-426

Laws, E. A., Redalje, D. G., Haas, L. W., Bienfang, P. K., Eppley, R. W., Harrison, W G., Karl, D. M., Marra, J.

This article was presented by Dr H. R. Skjoldal, Bergen, Norway
(1984). High phytoplankton growth and production rates in oligotrophic Hawaian coastal waters. Limnol. Oceanogr. 29: 1161-1169

Malone, T C. (1980). Algal size. In: Morris, I. (ed.) The physiological ecology of phytoplankton. Blackwell Scientific Publications, Oxford, p. 433-463

Maynard Smith, J. (1974). Models in ecolgoy. Cambridge University Press, Cambridge

McNaughton, S. J, (1988). Diversity and stability. Nature Lond. 333: 204-205

Monod, J. (1942). Recherches sur la croissance des cultures bacteriennes. Hermann et Cie, Paris

Parsons, T. R., Takahashi, M., Hargrave, B. (1977), Biological oceanographic processes. Pergamon Press, Oxford

Pengerud, B., Skjoldal, E. F., Thingstad, T F. (1987). The reciprocal interaction between degradation of glucose and ecosystem structure. Studies in mixed chemostat cultures of marine bacteria, algae, and bacterivorous nanoflagellates. Mar Ecol. Prog. Ser. 35: 111-117

Raven, J. A. (1988). Limits to growth. In: Borowitzka, M. A. Borowitzka, L. J. (eds.) Micro-algal biotechnology. Cambridge University Press, Cambridge, p. 331-356

Riley, G. A. (1963). Theory of food chain relations in the Ocean. In: Hill, M. N. (ed.) The sea, Vol. 2. Wiley, New York, p. 438-463

Rosenzweig. M. L., MacArthur, R. H. (1963). Graphical representation and stability conditions for predator-prey interactions. Am. Nat. 97: 209-223

Ryther, J. H. (1969). Photosynthesis and fish production in the sea. The production of organic matter and its conversion to higher forms of life vary throughout the world ocean. Science 166: 72-76

Sakshaug, E., Andresen, K., Myklestad, S., Olsen, Y (1983) Nutrient status of phytoplankton communities in Norwegian waters (marine, brackish, and fresh). J. Plankton Res. 5: $175-196$

Sakshaug, E., Olsen, Y (1986). Nutrient status of phytoplankton blooms in Norwegian waters and algal strategies for nutrient competition. Can. J. Fish. Aquat. Sci. 43: 389-396

Sheldon, R. W., Prakash, A., Sutcliffe, W. H. (1972). The size distribution of particles in the ocean. Limnol. Oceanogr. 17: $327-340$

Sherr, B. F., Sherr, E. B., Hopkinson, C. S. (1988). Trophic interactions within pelagic microbial communities: indications of feedback regulation of carbon flow. Hydrobiologia 159: $19-26$

Sherr, B. F., Sherr, E. B, Paffenhöfer, G.-A. (1986). Phagotrophic protozoa as food for metazoans: a missing trophic link in marine pelagic food webs? Mar. Microb. Food Webs 1: 61-80

Smith, F. E. (1969). Effects of enrichment in mathematical models. In: Eutrophication: causes, consequences, correctives. Proc. Natl. Acad. Sci., Washington, D. C., p. 631-645

Smith, R. E. H., Kalff, J. (1982). Size-dependent phosphorous uptake kinetics and cell quota in phytoplankton. J. Phycol. 18: 275-284

Thingstad, T F., Pengerud, B. (1985). Fate and effect of allochtonous organic material in aquatic microbial ecosystems. An analysis based on chemostat theory. Mar. Ecol. Prog. Ser. 21: 47-62

Tilman, D., Kilham, S. S., Kilham, P. (1982). Phytoplankton community ecology: the role of limiting nutrients. Ann. Rev. Ecol. Syst. 13: 349-372

Veldkamp, H. (1976). Continuous culture in microbial physiology and ecology. Meadowfield Press, Durham

Manuscript first received: November, 29, 1989

Revised version accepted: March 14, 1990 